\title{
THE EVALUATION PROCESS IN INDIVIDUALIZED AND SELF- INSTRUCTIONAL LANGUAGE PROGRAMS
}

\author{
EDNA AMIR COFFIN \\ Center for Near Eastern Studies, \\ University of Michigan, \\ Ann Arbor, Michigan 48109, USA
}

One of the most important functions which a language instructor performs is the evaluation of students' work, in terms both of ongoing progress, and of the success achieved by students at the end of the contracted learning period. The sum total of this evaluation, both the ongoing and the final, is rendered in the instructor's judgment of the students' achievement and is translated in most conventional institutions of higher learning into a letter grade or a final written report. Since self-instructional language programs, by definition, lack one ingredient present in regular classroom instruction the language instructor - they must have alternative means and procedures for evaluating students' work.

Several existing programs of individualized and supervised self-instruction have addressed themselves to this issue and have provided alternative viable systems of evaluation. The self-instructional programs which have ignored or paid little attention to this all important aspect of a language program, have done so at the expense of the quality of their offerings, and have neglected to give their students meaningful and clear indications of their degree of mastery of new language skills. What shape the process of evaluation takes and how it is incorporated in self-instructional language programs depends on the objectives of such programs and on the basic features which determine their character. In general, evaluation procedures cannot be separate and independent of the totality of the learning experience, for they are an integral part of the instructional program. Fair and reliable measurement of students' achievement can only be arrived at if the testing reflects the objectives and procedures which are part of the learning process.

In this paper evaluation procedures in two existing programs of individualized instruction will be discussed: the Personalized System of Instruction (PSI) and the Self-Instructional Language Programs (SILP) which follow the model set by the National Association of Self-Instructional Language Programs (NASILP).

PSI was developed as an alternative learning mode to classroom instruction. Developed by the psychologist Fred Keller and his associates, in this system students move through course material in small steps. They work with special self-instructional materials and at the end, when all requirements of the program are met, are considered to have successfully completed the instructional process. (1, part II, p. 5) The five defining features of PSI courses are that: (1) they are individually paced; (2) they are mastery oriented; (3) they are student proctored; (4) they use printed study guides for communication of information; and (5) they incorporate into the programs a set of 
lectures for stimulating and motivating students (the lectures are not used for instructional purposes). (2, p. 1029)

The PSI method can be easily adaptable for language learning purposes for students who wish to attain proficiency in the passive language skills. The individual learner can acquire these skills by himself, following directed activities and explanations, and he is not dependent on group activities. The objectives of such a language learning program are restricted to the areas of developing reading skills, the acquisition of a passive reading vocabulary, the introduction to the grammatical features of the target language (TL), and when deemed necessary, the development of some listening-comprehension ability through the extensive use of language tapes. Active features of the language, such as oral communication, necessitate the presence of at least a speaker and a listener, and for the best results these activities should be supervised by a trained instructor who can give helpful feedback and correct errors. Such active skills cannot be fully developed in PSI which stresses individualized learning at a pace set by the learner, and does not include an instructor as a regular resource person.

PSI can thus adequately meet the needs of students who wish to attain a reading comprehension in a language they intend to use for research purposes or for other purposes which do not require active control of the language. It offers a viable alternative for those who wish to work on their own and set their own pace in acquiring these limited goals.

One of the excellent features of PSI is that it contains a built-in system of evaluation and immediate feedback. After each unit, students must take a quiz, which they must pass with a perfect score to indicate and demonstrate full mastery of a limited body of material before they can proceed to the next unit. After taking a quiz, the students' work is evaluated immediately by student-proctors. There is no penalty for not passing a quiz with a perfect score, but the students who have not passed must be tested again on the same body of material. Students are able to move at their own pace. When they feel prepared, they take a unit quiz. The demand for full mastery of material is a sound principle which ensures that students understand a certain concept before moving on to the next one. The self-pacing is subject to the constraints of time, as students contract to finish a set number of units in a given learning period. Theoretically they can be tested on each unit many times, (the quizzes on the same unit are not identical - but they cover the same materials); however, realistically, the number of times students can repeat a quiz is limited by the fact that they must finish the number of units contracted for the given learning period (usually ten to fifteen weeks). While some students can finish the course in less time than is allowed, extensions are usually not granted beyond the term for those who have not completed the required units. Students who do not finish the prescribed number of units, fail the course. In PSI language courses, tests focus on reading comprehension, recognition of vocabulary as well as mastery of grammatical structures introduced in the learning units. The quizzes, which are evaluated by student-proctors, are objective tests which can be easily scored. In some institutions PSI is modified by the introduction of a final examination which determines the letter grade by which students who participate in the program are finally evaluated. This examination is evaluated by an instructor. The final examinations given to PSI students are identical to the ones given in a course taught in a conventional classroom. Thus, regardless of mode of learning, be it PSI or conventional classroom instruction, the results of the final test are evaluated using the same criteria, and determine the final grades.

The unit quiz evaluations are not based on comparison of results of different students' 
achievements. Complete mastery is demanded of each individual student. The pacing of learning, time spent mastering the material, and the degree of difficulty experienced by each student vary; however, the results must be identical: a perfect score. The final examination, on the other hand, is judged on a comparative basis as well as using more absolute criteria; less than complete mastery is acceptable and is translated into a letter grade reflecting the achievement of students relative to other students, as well as in terms of mastery of the materials.

The NASILP model of supervised self-instructional language programs differs from that of PSI programs both in its objectives and in its procedures, as well as in the evaluation process. These supervised SILP programs were set primarily as a practical solution to the growing needs of students for opportunities to learn languages not of fered in the regular university curriculum. While they do present an alternative to the conventional classroom mode of instruction, they were not set primarily as such, and were not intended to take the place of regular classroom instruction. Such programs (SILP) have a structure and resources which enable students to make reasonable progress and achieve a limited mastery of language skills. The practical command of the TL is emphasized, and thus the program is designed to develop the skills necessary for verbal communication and oral comprehension. Materials are selected which are suitable to the objectives of the program, and the learning procedures suggested differ from those of PSI, as group interaction is necessary. The main resources at the student's disposal are written and taped materials based on the audio-lingual approach, instructions and guidelines for activities, as well as obligatory tutorial sessions. The 2-3 hours of weekly tutorials consist of meetings of groups of 2-4 students with native speakers of the TL who function as drill masters and monitors but not as instructors. Speaking is practiced in the tutorial sessions, which are conducted entirely in the TL. The self-instructional portion of the program, i.e. the directed work which the student does on his own, prepares the student for the tutorials in which he has a chance to practice newly acquired language skills. Speaking, active control of vocabulary items, acceptable pronunciation as well as active use of new grammatical structures are the basic features of the TL emphasized in SILP. Reading comprehension and writing are considered secondary in many SILP undertakings, although NASILP is currently considering ways to incorporate these skills into the program. (Eleanor Jorden; Edna Amir Coffin, papers presented in panel on reading and writing skills in SILP, NASILP annual conference, Utica, New York, 1977).

The evaluation procedures of SILP differ considerably from the ones used in PSI, as the two programs have different objectives and procedures of learning as well. The evaluation procedures used in SILP have two main objectives: A. to evaluate the individual student's work; and B. to evaluate and control the standards and quality of the program as a whole. Thus each individual's progress is measured and evaluated, and the sum total of the achievements of the different individuals who participate in the program provides a basis for the evaluation of its effectiveness. There is no on-going process of evaluation of student's work as exists in a regular classroom, and there are no unit quizzes similar to the ones which are such an integral part of the PSI. Students get feedback from the tutors about some aspects of their verbal production, and are corrected for pronunciation and use of vocabulary; however, their work and progress are not fully evaluated till the end of the term. At the end of the term, an outside examiner is brought in to administer a final test, the results of which are used to provide an evaluation of the student's work. The outside examiner is a person who has the proper academic training and credentials in the $T L$ and is usually actively engaged in its instruction in a recognized academic institution. 
The examiner is also thoroughly familiar with the materials used in SILP as well as with the techniques used in such a program, and is thus able to construct the final examination accordingly.

The decision to have such a final examination rather than the periodic unit quizzes administered in PSI is not based on an ideological principle, but is rather a result of practical considerations. Since there are no qualified academic persons to construct, administer and evaluate the periodic unit tests, the testing procedure is deferred to the end of the contracted term of learning, at which point the student must be tested on the entire amount of material covered during the term. Full mastery is not required, and grades are given on the basis of performance in the test, using comparative as well as absolute standards of judgment.

The final examination occupies a relatively short time of the student's total learning experience. A 30-45 minutes oral examination is administered to each individual who has to demonstrate what he has learned during the previous ten or fifteen weeks. The preparation of students for such an oral test is of utmost importance as the test is administered only once during the semester and cannot be repeated. Just as students are instructed in detail how to proceed in their weekly activities, they are also instructed in detail as to how to prepare themselves for the final test. Ideally sample tests are available to students, in addition to clear guidelines, so that they can visualize the test and the procedures used by the examiner. (3, pp. 15-25)

As the emphasis in SILP is on oral skills, the individualized examination in its entirety is an oral test. It progresses from an informal personal interview in the TL to a more formal manipulation of materials, and it emphasizes speech production as well as listening. comprehension. The test is conducted in the $\mathrm{TL}$, and English is used only on rare occasions, not for prompting, but for social conversation to ease the anxiety of students.

The oral examinations administered in SILP vary somewhat with different examiners; however, the following features are common to most such tests:

\section{A personal interview}

The first few minutes are spent conversing with the student in the TL. Beginning language students are asked basic questions of information about themselves and their immediate surroundings. More advanced students can talk about their past experiences, future plans as well as other general topics of interest to examiner and student. This personal interview not only tests the student's ability to respond in the $\mathrm{TL}$, but also establishes some informal personal contact between the examiner and the student.

2. Rapid responses to questions posed by the examiner

The examiner asks questions from a prepared list. The questions are based on materials included in the lessons. The responses have to be spontaneous and immediate. Students are evaluated according to the appropriateness of their responses, the correctness of their speech, as well as their fluency and immediacy of response.

This is an excellent technique for testing students' comprehension, their control of various vocabulary items, as well as the degree of preparedness in the specific materials introduced in the course. The questions may be random, not necessarily related to one another, but they are all based on the vocabulary covered in the semester and have contextual reference to the units. The response can vary from ones which stick closely to the contexts in the book, to more adventurous attempts 
by students to express themselves - in either case, they have to be appropriate responses to the questions posed.

3. Students are presented with contextual situations to which they are asked to respond Situations have been used extensively in oral testing in FSI materials and other language programs with an audio-lingual orientation. A context or situation is presented to the student, and the student has to play a role within the given situation. The type of responses the student must give are not free but are contextbound; however, he is given a limited freedom to chose the exact phrasing of his responses.

4. Activities which elicit grammatical structures

They may be in the form of substitutions, transformations, forming questions to given responses, completions or other similar activities. This is a familiar format for the students who have drilled many of the new structures using these techniques. Linguistic as well as non-linguistic (pictures, numbers) cues are given by the examiner in order to elicit exact responses from the student. These activities can be easily scored, as there is usually but one correct response to each cue.

5. Listening comprehension is tested in several ways

Students are asked to listen to a passage, which is either recorded on tape or read to them by the examiner, and are asked to indicate that they understood the passage in full. The passage is new to them, but is constructed from materials which are thoroughly familiar to them. Comprehension can be checked by asking students to answer content questions, to select correct answers from sets of possibilities given to them, or to indicate whether a statement is true or false in relation to the passage they heard. At more advanced stages students may be asked to form their own content questions to the passage, or to produce an oral summary of the passage they heard.

6. In intermediate and advanced levels (these terms are used in relation to the SILP objectives) students are required to give a demonstration of their ability to produce sustained speech

They are given specific topics, or a list of topics from which they can select one, and are asked to give an extended oral discussion of the suggested topic. The topics are closely related to the passages introduced to the students during the semester. Students are expected to develop coherent ideas in the TL and sustain the discussion for 2-3 minutes, or longer.

7. If texts are used which do not employ transcription but rather depend on different systems of alphabet, students are often tested on reading as well

They are asked to translate a text, or to answer questions about a written passage, or to read the passage out loud. In the last type of activity, pronunciation is tested as well as the mechanical aspects of reading.

8. After having been rejected as a legitimate activity in many audiolingual programs, translation from English to $T L$ is regaining respectability once again

An oral translation of a passage or individual sentences can be incorporated into such an examination in order to test specific language structures, as well as vocabulary items. The difficulty and length of the translation is determined by the degree of language mastery. Translation is a challenging activity which integrates many aspects of the language into one activity, and can be used as the final component of the oral test.

Evaluating the student's performance in such a test does not present outstanding 
difficulties for an experienced language instructor, who serves as an examiner. While there are some subjective judgments to be made, much of the test is constructed in such a manner that much of the evaluation can be objective.

The SILP evaluation procedure has two main shortcomings: 1 . it produces a great deal of anxiety among students; 2 . it lacks the aspect of the ongoing evaluation and relies on the one final test as the main criterion for the evaluation of the student's performance

There are a couple of features unique to SILP which contribute to students' anxiety during the final examination period. The students are not acquainted with the outside examiner who tests them for their achievements. The resource people with whom the students have continous contact during the term are the tutors, who are often their peers in school. The examiner is not only a stranger but is also in an authority position with a formal role to play in the program, and is a qualified instructor. The personal interaction with such a person differs considerably from that to which the student is accustomed. The other main factor which produces unusual anxiety is the fact that the one testing period is used as the main and often only criterion for evaluating the students' work.

While students' anxiety cannot be totally eliminated, it can be somewhat alleviated if steps are taken to develop on-going evaluation procedures to supplement the basis on which students' performance is evaluated. PSI unit quizzes can be used as models for constructing such tests. They should be objective and easy to score.

PSI and SILP have developed testing and evaluation concepts and techniques which are useful not only for individualized and self-instructional language programs. The concept of testing as a means for demonstrating full mastery of individual units and limited materials is a very sound pedagogical principle, which can contribute to the quality of any language program. The lengthy oral examination administered in SILP re-emphasizes the necessity to test oral skills by an oral test. Much too often, while oral skills are emphasized in conventional language classrooms, they are rarely tested in an organized and formal manner. SILP examiners have developed sound techniques for oral testing which can be modified and adapted to other modes of learning as well.

\section{REFERENCES \& BIBLIOGRAPHY}

'KULIK, James A.; Kozma, Robert B.; Smith, Beverly B.; Weitzer, William H., Manual for PSI Instructors: I. Study Guides; II. Readings; III. Appendices Center for Research on Learning and Teaching, the University of Michigan, Ann Arbor, 1976.

'TAVEGGIA, Thomas C.; "Personalized Instruction: a Summary of Comparative Research, 1967-1974", American Journal of Physics, Vol. 44, No. 11, November 1976.

3COFFIN, Edna Amir, "Preliminaries and Preparations for Examinations: Examiner's Report and Evaluation", Proceedings of the 1975 NASILP Conference, Neville, Edwin L., Jr., Ed. Canisius College, Buffalo, New York, September, 1975. 
BOYD-BOWMAN, Peter, "National Self-Instructional Program in Critical Languages", The Modern Language Journal, Vol. LVI, No. 3, March, 1972 pp. 163-167.

CHASTAIN, Kenneth, The Development of Modern Language Skills: Theory to Practice, McGraw Hill Book Co., 1961.

COFFIN, Edna Amir, "The Role of the Tutor in Second Language Acquisition" 1978 CAL.ERIC/CLL Series on Language and Linguistics, in press.

KULIK, James A.; Klik, Chen-Lin C.; Smith, Beverly B. "Research on the Personalized System of Instruction", Programmed Learning and Educational Technology, 13, February, 1976.

LADO, Robert, Language Testing, McGraw Hill, 1961.

MANLEY, T. M., "Linguistics and Self-Instruction in Chinese', Journal of the Chinese Language Teachers Association, 7, 1, 21-24, 1972.

MOREHOUSE, Ward; Boyd-Bowman, Peter "Independent Study of Critical Languages in Undergraduate Colleges", May, 1973. A final report to the Institute International Studies (DHEW/DE), Washington D.C. 